\title{
Mutations in the glycine receptor $\alpha 1$ subunit (GLRA1) gene in hereditary hyperekplexia pedigrees: evidence for non-penetrance of mutation Y279C
}

John B J Kwok, Salmo Raskin, Graeme Morgan, Sergio Antonio Antoniuk, Isac Bruk, Peter R Schofield

Garvan Institute of Medical Research, 384 Victoria Street, Darlinghurst, Sydney, NSW 2010, Australia

J B J Kwok

P R Schofield

Laboratorio Genetika, Alameda Augusto Stellfeld 1516,

Curitiba, Parana 80730-150, Brazil S Raskin

Department of Medical Genetics, Prince of Wales Children's Hospital, High Street,

Randwick, Sydney, NSW 2031, Australia G Morgan

Division of

Neuropediatrics, Pediatrics

Department, Hospital das Clinicas,

Universidade Federal

do Parano, Curitiba,

Parana 80730-150

Brazil

S A Antoniuk

I Bruk

Correspondence to: Professor Schofield, p.schofield@

garvan.unsw.edu.au
EDITOR-Hereditary hyperekplexia, or familial startle disease (OMIM 149400), is a rare neurological disease that is characterised by marked muscular hypotonia in affected infants and an exaggerated response or "startle" reflex to an unexpected stimulus. Positional candidate analysis has successfully identified the gene coding for the $\alpha 1$ subunit of the inhibitory glycine receptor (GLRA1) on chromosome 5q33-35 as the disease gene. ${ }^{1}$ The glycine receptor (GlyR) is a ligand gated chloride channel which mediates synaptic inhibition in the spinal cord and other brain regions. ${ }^{2}$ The majority of inherited mutations have been found in exons 6 and 7 of the GLRA1 gene, which code for the first and second transmembrane (TM) domains of the receptor. At present, six missense mutations, P250T, ${ }^{3}$ $\mathrm{Q} 266 \mathrm{H},{ }^{4} \mathrm{R} 271 \mathrm{~L},{ }^{16} \mathrm{R} 271 \mathrm{Q},{ }^{16} \mathrm{~K} 276 \mathrm{E},{ }^{5}$ and Y $279 \mathrm{C},{ }^{6}$ are inherited in a dominant manner. Two mutations, $\mathrm{I} 244 \mathrm{~N}^{7}$ and a deletion of exon 1 to 6 of the GLRA1 gene, ${ }^{8}$ can also result in a recessive phenotype, as detected in affected offspring of consanguineous parents. Finally, there are compound mutations ( $\mathrm{R} 252 \mathrm{H}$ and $\mathrm{R} 392 \mathrm{H}$ ) which, when inherited from the two parental alleles, give rise to hyperekplexia. ${ }^{9}$ In this report, we analysed the GLRA1 gene as the candidate for the disease locus in two families with hereditary hyperekplexia.

\section{Case reports}

The first pedigree (Fam-1) contains 20 members over three generations with 10 affected subjects (fig 1A). The female proband (III.13) from family 1 was prone to fall in response to any unexpected stimulus, such as a touch or a sharp sound, from the time she started walking. Falling was the result of momentary generalised stiffness of her trunk and limbs with loss of postural control. This symptom was present in a large number of male and female relatives, as shown in fig $1 \mathrm{~A}$, consistent with autosomal dominant inheritance of the disorder. Falling in affected members of the family was sudden, unpredictable, and uncontrollable. Falling was not accompanied by loss of consciousness and affected members were able to rise from the ground immediately after falling. The diagno- sis of hyperekplexia was made after publication of the paper by Morley et al. ${ }^{10}$ The proband was treated with clonazepam and remained symptomless for over 13 years.

The second pedigree (Fam-2) contains 10 members over three generations with five affected members (fig 1B). The proband (III.10) was a white female who had generalised hypertonia, jerks, irritability, constant crying, and divergent squint during the neonatal period (from 2 days of age). She started to walk at 1 year 2 months with frequent falls, mostly forwards. Nasal percussion or sounds elicited jerks. She is currently aged 12 years and even with $2 \mathrm{mg} /$ day clonazepam still presents with mild hypertonia of the limbs and jerks as before. The proband's 10 year old brother (III.9) presented at 6 days of age with generalised hypertonia, convergent strabismus (squint), and jerks on percussion of the dorsal nose. He started to walk at the same age as his sister, falling frequently, and has difficulty with fine motor activity. He has learning disabilities for which he is in a special class. He currently is treated with clonazepam but still presents with moderate hypertonia of the limbs and jerks on nasal percussion. The mother of the two children (II.3) is healthy and has never had any of the symptoms observed in either of her children.

Genomic DNA was isolated from peripheral leucocytes from a sample of pedigree members (fig 1). Since the majority of reported hyperekplexia mutations occur in exons 6 and 7 of the GLRA1 gene, we used primers to PCR amplify $332 \mathrm{bp}$ and $280 \mathrm{bp}$ products from genomic DNA templates. ${ }^{1}$ PCR products were sequenced directly on both strands using fluorescent Big-Dye terminator chemistry (PE Biosystems, NJ, USA). As shown in fig $1 \mathrm{~A}$, the affected subjects of family 1 were heterozygous for a missense mutation at nucleotide position 1192 ( $\mathrm{G}$ to $\mathrm{A})$, which substitutes an arginine with a glutamine residue at codon position 271 (R271Q). This mutation is located at the extracellular end of the chloride channel domain of the receptor and results in a marked decrease in sensitivity to glycine. ${ }^{11-13}$ The mutation was inherited in an autosomal domi- 

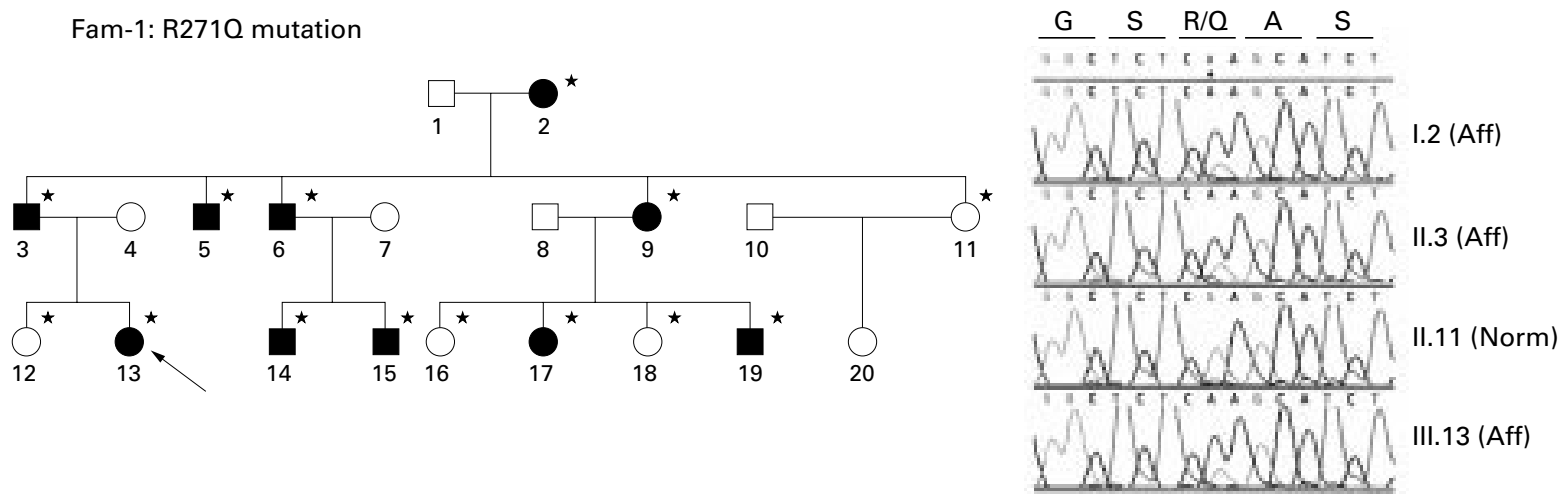

B

Fam-2: Y279C mutation
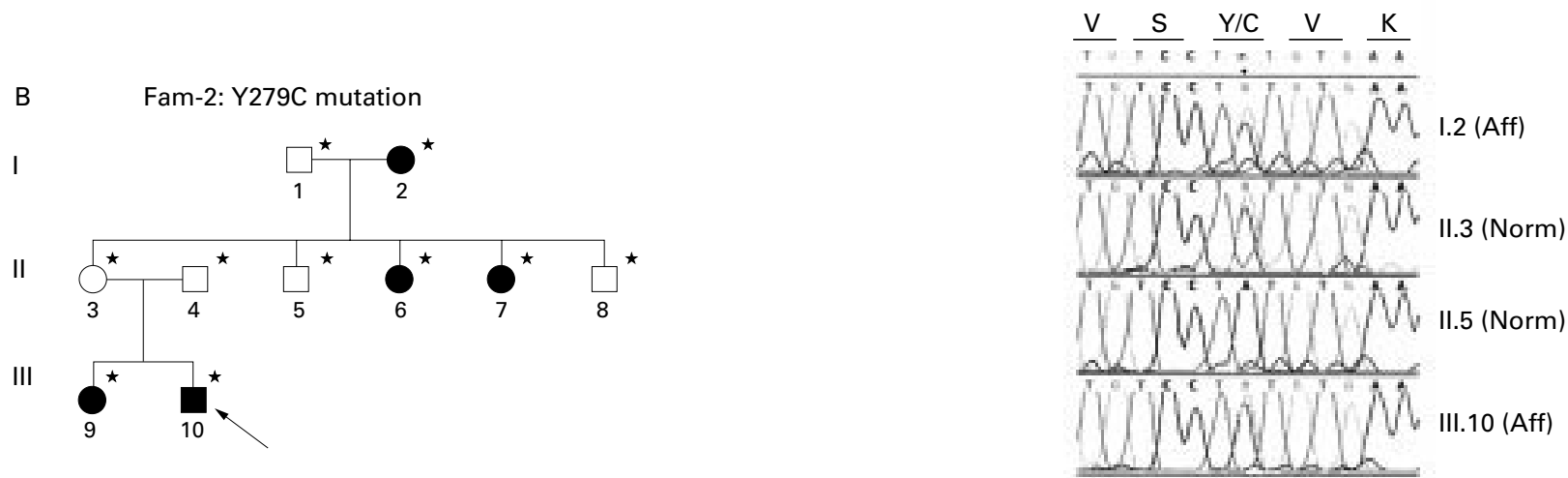

Figure 1 Sequence analysis of the GLRA1 gene in two hereditary hyperekplexia pedigrees. The probands (indicated by arrows) are part of two complex three generational pedigrees. Asterisks indicate family members screened for the presence of missense mutations in the GLRA1 gene. (A) A missense mutation (R271Q) in the GLRA1 gene of Fam-1 pedigree. The presence of the mutation is indicated by a double peak ( $G$ and $A$ ) in the sequence electropherograms of affected (Aff) subjects and not in normal (Norm) members. (B) Missense mutation (Y279C) in the GLRA1 gene of the Fam-2 pedigree. Sequence analysis of exon 7 of the GLRA1 gene showed an unaffected obligate carrier (II.3) of the mutation.

nant manner and with complete penetrance of the mutant GLRA1 allele, as all the R271Q mutation carriers were affected. In family 2, affected subjects had a missense mutation at nucleotide position 1216 (A to G), which substitutes a tyrosine with a cysteine residue at codon position 279 (Y279C). This mutation is situated in the short extracellular domain between transmembrane domains 2 and 3 and has been reported to disrupt the ability of the receptor to convert agonist binding to channel activity. ${ }^{14}$ In contrast to the R271Q mutation in family 1 , there appeared to be incomplete penetrance of the Y279C mutation as one clearly unaffected subject, II.3, carried the mutation and transmitted it to her affected children (III.9 and III.10).

\section{Discussion}

This is the first report of a non-penetrant hyperekplexia mutation and only the second non-penetrant mutation described for the ligand gated ion channel receptor superfamily. Incomplete penetrance has also been observed in autosomal dominant nocturnal frontal lobe epilepsy, which is caused by the S284F missense mutation in the neuronal nicotinic acetylcholine receptor $\alpha 4$ subunit. ${ }^{15}$ The presence of four obligate carriers of the S284F mutation in a large pedigree with 21 affected members suggests that there are compensatory mechanisms which can override the receptor defect. In the mouse, the inheritance of a homozygous microdeletion of the Glra1 gene (oscillator mutation) leads to the complete lack of GlyR $\alpha 1$ protein in the spinal cord of the animal and is lethal. ${ }^{16} \mathrm{~A}$ similar deletion mutation has been described in humans. ${ }^{8}$ However, the homozygous offspring of a consanguineous mating suffered only from typical hyperekplexia symptoms ${ }^{8}$ suggesting that the loss of the GlyR $\alpha 1$ protein can also be compensated for to some degree in humans. The observation of the escapee in the family 2 pedigree supports this hypothesis. In the postsynaptic membrane, the glycine receptor exists as a complex with other molecules such as the cytoskeletal protein gephyrin, which may modulate the effect of agonist binding and channel activity. ${ }^{17}$ The actions of the other major inhibitory neurotransmitter $\gamma$-aminobutyric acid (GABA) may also partially compensate for the loss of GlyR function as hyperekplexia is effectively treated with benzodiazapines. ${ }^{18}$ Thus, it is possible that environmental or genetic factors effectively compensate for the pathogenic effects of the Y279C mutation in the observed non-penetrant escapee. The elucidation of these factors will have important implications for the understanding of synaptic neurotransmission.

This work was supported by the Australian National Health and Medical Research Council (Block Grant 993050). 
1 Shiang R, Ryan SG, Zhu Y, Hahn AF, O'Connell P, Wasmuth JJ. Mutations in the $\alpha 1$ subunit of the inhibitory glycine receptor cause the dominant ne

2 Grenningloh G, Schmieden V, Schofield PR, Seeburg PH, Siddique T, Mohandas TK, Becker CM, Betz H. Alpha subunit variants of the human glycine receptor: primary structures, functional expression and chromosomal localisation of the corresponding genes. EMBO F 1990;9:771-6.

3 Saul B, Kuner T, Sobetzko D, Brune W, Hanefeld F, Meinck HM, Becker CM. Novel GLRA1 missense mutation (P250T) in dominant hyperekplexia defines an intracellular determinant of glycine receptor channel gating. $f$ Neurosci 1999;19:869-77.

4 Milani N, Dalpra L, del Prete A, Zanini R, Larizza L. A novel mutation (Gln266His) in the alpha 1 subunit of the inhibitory glycine-receptor gene (GLRA1) in hereditary hyperekplexia. Am f Hum Genet 1996;58:420-2.

5 Seri M, Bolino A, Galietta LJV, Lerone M, Silengo M, Romeo G. Startle disease in an Italian family by mutation (K276E): the $\alpha$-subunit of the inhibiting glycine receptor. (K276E): the $\alpha$-subunit of
Hum Mutat 1997;9:185-7.

6 Shiang R, Ryan SG, Zhu YZ, Fielder TJ, Allen RJ, Fryer A, Yamashita S, O'Connell P, Wasmuth JJ. Mutational analysis of familial and sporadic hyperekplexia. Ann Neuro 1995;38:85-91

7 Rees MI, Andrew M, Jawad S, Owen MJ. Evidence for recessive as well as dominant forms of startle disease (hyperekplexia) caused by mutations in the alpha-1 subunit of the inhibitory glycine receptor. Hum Mol Genet 1994;3: 2175-9.

8 Brune W, Weber RG, Saul B, von Knebel Doeberitz M, Grond-Ginsbach C, Kellerman K, Meinck HM, Becker CM A GLRA1 null mutation in recessive hyperekplexia challenges the functional role of glycine receptors. Am $\mathcal{F}$ Hum Genet 1996;58:989-97.

9 Vergouwe MN, Tijssen MAJ, Peters ACB, Wielaard R, Frants RR. Hyperekplexia phenotype due to compound Frants RR. Hyperekplexia phenotype due to compound 1999;46:634-8.
10 Morley DJ, Weaver DD, Garg BP, Markand O. Hyperekplexia: an inherited disorder of the startle response. Clin Genet 1982;21:388-96.

11 Langosch D, Laube B, Rundström N, Schmieden V, Bormann J, Betz H. Decreased agonist affinity and chloride conductance of mutant glycine receptors associated with human hereditary hyperekplexia. EMBO f 1994;13:42238.

12 Rajendra S, Lynch JW, Pierce KD, French CR, Barry PH, Schofield PR. Startle disease mutations reduce the agonist sensitivity of the human inhibitory glycine receptor. F Biol Chem 1994;269:18739-42.

13 Rajendra S, Lynch JW, Pierce KD, French CR, Barry PH, Schofield PR. Mutation of an arginine residue in the human glycine receptor transforms $\beta$-alanine and taurine from agonists into competitive antagonists. Neuron 1995; 14:169-75.

14 Lynch JW, Rajendra S, Pierce KD, Handford CA, Barry PH, Schofield PR. Identification of intracellular and extracellular domains mediating signal transduction in the inhibitory glycine chloride channel. EMBO f 1997;16:110-20.

15 Steinlein OK, Mulley JC, Propping P, Wallace RH, Phillips HA, Sutherland GR, Scheffer IE, Berkovic SF. A missense mutation in the neuronal nicotinic acetylcholine receptor $\alpha 4$ subunit is associated with autosomal dominant nocturnal frontal lobe epilepsy. Nat Genet 1995;11:201-3.

16 Kling C, Koch M, Saul B, Becker CM. The frameshift mutation oscillator GLRA1 (spd) produces a complete loss of glycine receptor $\alpha-1$ polypeptide in mouse central nervous system. Neuroscience 1997;78:411-17.

17 Betz H. Gephyrin, a major player in GABAergic postsynaptic membrane assembly? Nat Neurosci 1998;1:541-3.

18 Ryan SG, Sherman SL, Terry JC, Sparkes RS, Torres MC, Mackey RW. Startle disease or hyperekplexia: response to clonazepam and assignment of the gene (STHE) to chromosome 5q by linkage analysis. Ann Neurol 1992;31: 663-8. 